\section{Diagnosis and treatment of Parkinson's disease}

\section{Anosmia is a common finding}

EDITOR,-Niall Quinn's review on the recognition and differential diagnosis of parkinsonism ${ }^{1}$ omits an important point-namely, that at least $70 \%$ of patients with idiopathic Parkinson's disease have a defective or absent sense of smell. ${ }^{23}$ About $90 \%$ of patients have rigidity and akinesia, and hence impairment of the sense of smell would be the second commonest feature of this condition, at least equalling tremor in its frequency of occurrence. About half of patients are aware of this defect, and it is suspected, although not yet proved, that anosmia may precede the onset of the motor aspects of idiopathic Parkinson's disease.

This observation has important clinical consequences. If one suspects a patient to have idiopathic Parkinson's disease and the result of a simple bedside test of olfaction is normal then the diagnosis should be questioned. In progressive supranuclear palsy (Steele-Richardson syndrome), which may simulate idiopathic Parkinson's disease, olfaction is normal. ${ }^{4}$ Furthermore, provisional information suggests that patients with benign essential tremor also have normal smell identification scores. ${ }^{3}$ This might not permit the distinction from benign tremulous Parkinson's disease as ou limited data suggest that olfaction is normal in this rare variety of parkinsonism.

An ideal test for olfactory identification is the University of Pennsylvania smell identification test. Unfortunately, this is quite expensive, but preliminary assessment may be made with everyday odours such as chocolate, orange peel, coffee, rose, and vanilla. As long as local nasal disease is excluded an important clinical sign may be documented.

C M HAWKES

Department of Clinical Neurology, Ipswich Hospital,
Ipswich IP4 5PD

1 Quinn N. Parkinsonism-recognition and differential diagnosis. $B M 7$ 1995;310:447-52. (18 February.)

2 Doty RL, Deems DA, Stellar S. Olfactory dysfunction in parkinsonism: a general deficit unrelated to neurologic signs, disease stage or disease duration. Neurology 1988;38:1237-44.

3 Hawkes CH, Shephard BC. Olfactory impairment in Parkinson's disease: evidence of dysfunction measured by olfactory evoke potentials and smell identification tests. Ann Neurol 1992;32: 248.

4 Wenning GK, Shephard B, Hawkes CH, Lees A, Quinn N Olfactory function in progressive supranuclear palsy and corticobasal degeneration. I Neurol Neurosurg Psychiatry 1994; 57:251-2.

5 Busenbark KI, Huber SJ, Greer G, Pahwa R, Koller WC Olfactory function in essential tremor. Neurology 1992;42: 1631-2.

\section{Anticholinergic drugs are not contraindicated after iridotomy}

EdTOR,-In his review of the drug treatment of Parkinson's disease Niall Quinn states mistakenly that anticholinergic drugs are contraindicated in narrow angle glaucoma. ${ }^{1}$ Similar misleading advice continues to be published in various pharmacopoeias (for example, the British National Formulary) with reference to other drugs with anticholinergic effects, including antidepressants and bladder relaxants. In addition, general practitioners commonly cite a history of glaucoma

\section{Advice to atithor}

We prefer short letters that relate to recently published article and we are unlikely to publish letters longer than 400 words and containing over five references. Letters may be shortened. Your letters should be typed with double spacing and include a word count. All authors need to sign the letter and provide one current appointment and address. We encourage you to declare any conflict of interest. Please enclose a stamped addressed envelope if you require an acknowledgment.

as a reason for not dilating patients' eyes when screening for diabetic retinopathy. ${ }^{2}$

When acute narrow angle glaucoma is confirmed laser iridotomy should be performed to prevent any recurrence; this renders pupil dilatation safe. Chronic open angle glaucoma, by definition, does not predispose to angle closure. When doubt persists the eye department should be consulted.

Acute narrow angle glaucoma is rare and confined almost exclusively to people with severe hypermetropia and elderly people. Good practice dictates that patients should always be warned about potential side effects of newly prescribed drugs so that help can be requested at an early stage and permanent harm prevented. Current advice to doctors on the use of anticholinergic drugs, however, seems to be in need of review. Many patients with relatively common conditions are at risk of being deprived of their most suitable drug treatment because of exaggerated and erroneous fears of precipitating a relatively uncommon condition.

ANDREW FINK

Chaim Sheba Medical Centre,

Maurice and Gabriela Goldschleger Eye Institute,

Tel-Hoshomer, Israel

1 Quinn N. Drug treatment of Parkinson's disease. BMf 1995; 310:575-9. (4 March.)

Fink A, Wright L, Wormald R. Detection and prevention of treatable visual failure in general practice: room for improvement? Br $\mathcal{F}$ Gen Pract 1994;44:587-9.

\section{Author's reply}

EDrToR,-I agree with $\mathrm{C} \mathrm{H}$ Hawkes that the question of impaired olfaction is of interest in the differential diagnosis of parkinsonism. Although I did not address this in my review because of limitations on space, colleagues (including Hawkes) and I have shown that a score of 25/40 in the University of Pennsylvania smell identification test gives a sensitivity of $77 \%$ and a specificity of $85 \%$ in differentiating idiopathic Parkinson's disease from progressive supranuclear palsy, corticobasal degeneration, and multiple system atrophy. ${ }^{1}$ On a group basis, olfaction in the first two of these conditions did not differ significantly from that in normal controls, but olfaction in the group with multiple system atrophy, while significantly better than that in the group with idiopathic Parkinson's disease, was also significantly worse than that in the control group. Scores below the lower limit of the $95 \%$ confidence interval for controls were found in $51 \%$ of patients with idiopathic Parkinson's disease, $31 \%$ of those with multiple system atrophy, $20 \%$ of those with progressive supranuclear palsy, and none of seven with corticobasal degeneration. Interpretation of the diagnostic importance of olfactory impairment in individual cases rather than between groups must therefore be made with caution.

Andrew Fink takes me to task for stating that anticholinergic drugs are contraindicated in narrow angle glaucoma. He is correct in stating that if this has already been treated by iridotomy then these drugs are not contraindicated. Anticholinergic drugs can, however, cause blindness in patients who have not been treated by iridotomy by precipitating narrow angle glaucoma. Indeed, three such cases caused by benzhexol were reported in the $B M F$ in 1972 by Israeli ophthalmologists.

NIALL QUINN

Institute of Neurology,

Reader in clinical neurolog

London WC1N $3 B$

1 Wenning GK, Shephard B, Hawkes C, Petruckevitch A Lees A, Quinn N. Olfactory function in typical parkinsonia syndromes. Acta Neurol Scand 1995;91:247-50.

2 Friedman Z, Neumann E. Benzhexol-induced blindness in Parkinson's disease. BMF 1972;i:605.

\section{Alcoholism and rising mortality in the Russian Federation}

EdrToR,-Michael Ryan's article ${ }^{1}$ and the press coverage that followed it highlight how little is known in the West about the human tragedy currently unfolding in Russia. Although the nonIslamic republics of the former Soviet Union have a long tradition of high alcohol consumption, until recently epidemiological research on it was suppressed as this was the reponsibility of the Ministry of Internal Affairs. ${ }^{2}$ This latter factor may explain the remarkable absence of references to alcohol in major Western reports on health in the former Soviet Union.

Ryan notes that if the change in life expectancy coinciding with Gorbachev's antialcohol campaign had been seen in a Western country it would seem improbable and some might be inclined to dismiss it as propaganda. We have also experienced disbelief in the magnitude of this effect, but considerable evidence supports it. This includes the observation that similar changes took place in all the European republics of the former Soviet Union (figure). Each experienced a dramatic increase between 1985 and 1986, typically of the order of two years. Since then the direction of change has reversed dramatically in all republics. Studies in the Russian literature of experience at local level also report quite large reductions in rates of admission to hospital and death rates (in both cases over $30 \%$ ), due in large part to a reduction in violence related to alcohol. ${ }^{3}$

There can now be little doubt that the campaign in 1985, described in detail by Tarschys, ${ }^{2}$ was extraordinarily effective. It involved a range of approaches, including reducing access through the closure of outlets and restricting sales to after $2 \mathrm{pm}$, increasing prices, police action, media campaigns, and the creation of antialcohol movements. Detailed analysis of consumption patterns, with allowance being made for illicit production, shows a considerable, if short lived, fall in consumption. ${ }^{4}$ This is all the more amazing given the strong 


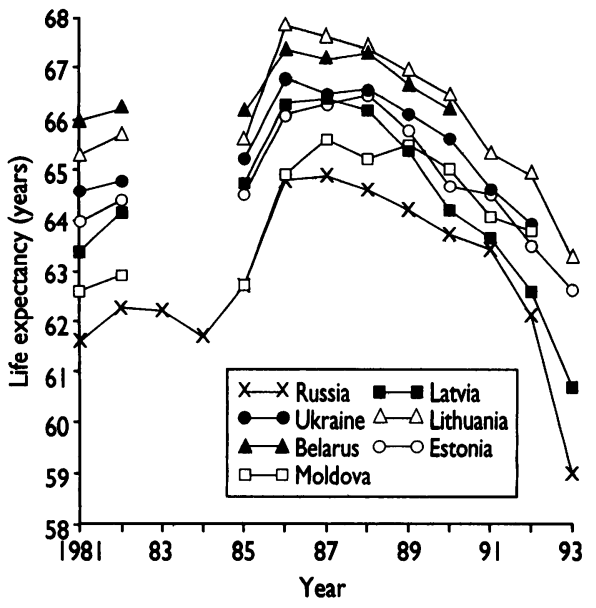

Life expectancy among males at birth in European republics of former Soviet Union (sources World Health Organisation, Unicef, and V Shkolnikov (personal communication)). Data for 1983-4 not available for some republics.

vested interests, not least in the Ministry of Finance, that opposed it. ${ }^{2}$

Although alcohol consumption began to increase again in the late $1980 \mathrm{~s}$, especially as a result of illicit production and diversion from state trading organisations, alcohol is unlikely to explain all the recent deterioration in life expectancy. ${ }^{5}$ As Ryan notes, much high quality epidemiological research is now being undertaken in the former Soviet Union, although there is little evidence that it is being acted on by policymakers either there or in the West. What is needed is a mechanism for bringing this work to a wider audience in both regions.

MARTIN MCKEE Senior lecturer LAURENT CHENET

Department of Public Health and Policy, Research fellow

Health Services Research Unit,

London School of Hygiene and Tropical Medicine,

London WC1E $7 \mathrm{HT}$

1 Ryan M. Alcoholism and rising mortality in the Russian Federation. $B M \mp$ 1995;310:646-8. (11 March.)

2 Tarschys $D$. The success of a failure: Gorbachev's alcohol policy, 1985-88. Europe-Asia Studies 1993;45:7-25.

3 Markov KV, Britov AN, Vedeneeva IA. Chastota upotrebleniia alkogolia i struktura prichin smerti muzhchin 40-54 let. Sovetskoe Zdravookhranenie 1990;(4):15-8.

4 Nemtsov AV. Uroven realnovo potriebleniya alkogolya v Rossiyskoi Federatsii (1981-1990gg). Sotsialnaya $i$ Klinicheskaya Psychiatriya 1992;4:46-53.

5 McKee M, Leon D. Deaths in Russia. Lancet 1994;344:1698.

\section{Improving the detection of glaucoma}

\section{Intraocular pressure of greater than $21 \mathrm{~mm} \mathrm{Hg}$ is an indication to refer}

EDrToR,-Ronald Pitts Crick and Maurice W Tuck argue that "to improve the present system of detecting glaucoma the trend to more comprehensive testing by optometrists needs to be encouraged." They suggest that patients should be referred if they have an intraocular pressure of $\geqslant 26 \mathrm{~mm} \mathrm{Hg}$ or an intraocular pressure of 22-25 mm $\mathrm{Hg}$ plus optic discs or visual fields with features characteristic of glaucoma. Under present regulations, however, a patient should be referred "if there appears to be signs of injury, disease or abnormality in the eye or elsewhere which may require medical treatment." ${ }^{23}$ The upper limit of normal introcular pressure is generally taken to be $21 \mathrm{~mm} \mathrm{Hg}$. Thus an intraocular pressure of 22-25 $\mathrm{mm} \mathrm{Hg}$, even in the absence of other features of glaucoma, is a sign of disease or abnormality in the eye. An optometrist who did not refer such a patient could be in breach of current regulations.
This needs to be clarified before optometrists can take a more active role in the screening of glaucoma.

St James's University Hospital, Consultant ophthalmologist

Leeds LSO TTF

1 Crick RP, Tuck $M$. How can we improve the detection of glaucoma? BMF 1995;310:546-7. (4 March.)

2 National Health Service (general ophthalmic service) regulations. London: HMSO, 1986.

3 National Health Service (general ophthalmic services) amendmen No 2 regulations. London: HMSO, 1989.

\section{Link between glaucoma and diabetes is disputed}

EDrTor,-Ronald Pitts Crick and Maurice W Tuck highlight the difficulties of screening for glaucoma and twice mentioned diabetes as an important risk factor. ${ }^{1}$ Tielsch et al have recently cast doubt on this tenet in ophthalmology. ${ }^{2}$ Using data from the Baltimore eye survey, they concluded that there is no evidence to support an association between diabetes and primary open angle glaucoma.

RICHARD REDMOND

Department of Ophthalmology,

Scarborough Hospital,

1 Crick RP, Tuck $M$. How can we improve the detection of glaucoma? BM7 1995;310:546-7. (4 March.)

2 Tielsch JM, Katz J, Quigley HA, Javitt JC, Sommer A. Diabetes,

intra-ocular pressure, and primary open-angle glaucoma in the

Baltimore eye survey. Ophthalmology 1995;102:48-53.

\section{Lipid lowering dietary advice}

EDrToR,-Scientists and practitioners agree that dietary modification should be the first step of any cholesterol lowering regimen, but H A W Neil and colleagues report that the reduction in concentrations of total cholesterol and low density lipoprotein cholesterol after dietary advice given in general practice to hypercholesterolaemic patients by a dietitian, practice nurses, or in a diet leaflet alone was small. ${ }^{1}$ The poor response seems to be related mainly to the low dietary compliance in poorly motivated patients. This agrees with our objective evaluations of the compliance to hypocholesterolaemic dietary prescriptions: on the basis of changes in the plasma fatty acid pattern, after two months on the diet only $40 \%$ of patients could be defined as good adherers, while $22 \%$ had a poor compliance and the remaining a variable adherence over time. ${ }^{2}$ Neil and colleagues conclude that a more intensive intervention than is normally available in primary care is probably necessary and a mass approach to dietary changes is needed.

Instead, better results have been obtained in 65 patients attending a lipid clinic $^{3}$ and in 45, 9 year old schoolchildren enrolled in a community project for control of chronic diseases. ${ }^{4}$ In the first study, dietary intervention was performed by a doctor and included the evaluation of a seven day food record, practical dietary recommendations, and distribution of a booklet suggesting the adoption of the Mediterranean diet. After six weeks, total cholesterol decreased by $11.3 \%$ and low density lipoprotein cholesterol by $15 \cdot 3 \%$ (from $7 \cdot 12$ (SD 0.5) $\mathrm{mmol} / \mathrm{l}$ to $6.31(0.7) \mathrm{mmol} / \mathrm{P}, \mathrm{P}<0.001$, and from $5.04(0.5) \mathrm{mmol} / \mathrm{h}$ to $4.27(0.6) \mathrm{mmol} /$, $P<0.001$, respectively) in 25 patients with moderate hypercholesterolaemia and by $9 \cdot 1 \%$ and $9.9 \%$ in 40 patients with severe hypercholesterolaemia (from $9.49(1.4) \mathrm{mmol} / \mathrm{l}$ to $8.76(1.7) \mathrm{mmol} / \mathrm{l}, \mathrm{P}<0.001$, and from 7.43 $(1.4) \mathrm{mmol} / \mathrm{l}$ to $6.70(1.8) \mathrm{mmol}, \mathrm{P}<0.001)$.
In the second study simple dietary advice was given to parents when blood was taken. This included a list of foods to be avoided and a list of suggested foods to be consumed at home and at school. As an example to start with, a standard isocaloric, moderate fat, moderate cholesterol diet was provided, together with practical information on food preparation. After six weeks, total cholesterol dropped by $14 \cdot 1 \%$ (from $4.58(0.8) \mathrm{mmol} / \mathrm{l}$ to $3.93(0.6) \mathrm{mmol} / \mathrm{h}, \mathrm{P}<0.001)$ and low density lipoprotein cholesterol by $16.9 \%$ (from 2.78 $(0.7) \mathrm{mmol} / 1$ to $2.31(0.5) \mathrm{mmol} / \mathrm{l}, \mathrm{P}<0.001)$. Both total cholesterol and low density lipoprotein cholesterol remained almost unchanged after 12 months $(3.94(0.6) \mathrm{mmol} / \mathrm{l}$ and $2.27(0.5) \mathrm{mmol}$, respectively).

The above data are similar to those obtained in the long term treatment with some cholesterol lowering drugs, suggesting the high efficacy of simple and low cost dietary advice and the need for a careful evaluation of the compliance to hypocholesterolaemic dietary prescriptions before starting drug treatment. "True dietary resistance" due to genetic factors should also be borne in mind.

FRANCESCO ANGELICO Senior research fellow ROBERTO VOLPE Research fellow

Istituto di Terapia Medica Sistematica,

Universita" "La Sapienza,"

00161 Rome,

Italy

1 Neil HAW, Roe L, Godlee RJP, Moore JW, Clark GMG, Brown $J$, et al. Randomised trial of lipid lowering dietary advice in general practice: the effects on serum lipids, lipoproteins and antioxidants. BMf 1995;310:567-73. (4 March.)

2 Ricci G, Angelico F, Amodeo P, Borgogelli C, Cantafora A, Montali A, et al. Objective evaluation of the compliance to hypocholesterolaemic dietary prescriptions. In: Noseda G, et al, eds. Diet and drugs in atherosclerosis. New York: Raven, 1980:23-8.

3 Volpe R, Angelico F, Arca M, Ginnetti MG, Ricci G, Urbinati G. Effects of simple dietary advice on serum lipids in severe and moderate primary hypercholesterolemia. In: Gotto AM et al mods. Treatrent of severe dyslipoprotenemi in cononary heart disease. Basle: Karger, 1992:226-30.

4 Angelico F, Del Ben M, Lentini P, Mazzarella B, Pannozzo F, Urbinati G, et al. Improved serum lipoprotein profile after simple dietary advice in children. In: Descovich GC et al, eds.
Atherosclerosis and cardiovascular disease. Bologna: Editrice Atherosclerosis and cardiovas

5 Xu CF, Angelico F, Del Ben M, Pannozzo F, Mazzarella B, Miller NE, et al. Polymorphisms at the apolipoprotein loci and response of plasma lipids to dietary change in Italian children. NMCD 1992;2:26-32.

\section{Magnesium in acute myocardial infarction}

EDrTOR,-Salim Yusuf and Marcus Flather ${ }^{1}$ offer no satisfactory explanation for the statistical incompatibility $(\mathrm{P}>0.0001$ for heterogeneity) between the inefficacy of magnesium in the fourth international study of infarct survival (ISIS-4) ${ }^{2}$ and the clearly positive pooled results of the 10 other trials of intravenous magnesium in acute myocardial infarction. Magnesium has been reported to protect contractile function in a dozen experimental models of myocardial ischaemia and reperfusion and is now known to act during the first few minutes of reperfusion. ${ }^{34}$ ISIS-4 was unique in that most patients underwent thrombolysis before being randomised to magnesium or control (to accommodate the factorial design). The interval was not recorded but most typically have been three or more hours after randomisation took place at a mean of seven hours from the onset of symptoms. The $30 \%$ of patients in ISIS- 4 who were not given thrombolytic treatment were randomised at a mean of 12 hours after the onset of symptoms, when spontaneous reperfusion of viable myocardium is unlikely to occur.

ISIS-4 was not designed to test for an antireperfusion effect of magnesium. Any subgroup analysis put forward to disprove such an effect 